\title{
UNILATERAL OLFACTORY SENSITIVITY \\ IN MULTIPLE SCLEROSIS
}

Kimberley P. Good, ${ }^{1}$ Isabelle A. Tourbier, ${ }^{2,3}$ Paul Moberg, ${ }^{2,3}$ Jennifer L. Cuzzocreo, ${ }^{4}$ Rena J. Geckle, ${ }^{5}$ David M. Yousem ${ }^{5}$ Dzung L. Pham, ${ }^{6}$ and Richard L. Doty ${ }^{2,3}$

${ }^{1}$ Department of Psychiatry and Psychology \& Neuroscience, Dalhousie University, Halifax, Nova Scotia, Canada

${ }^{2}$ Smell and Taste Center, Perelman School of Medicine, University of Pennsylvania, Philadelphia, PA

${ }^{3}$ Department of Otorhinolarynology: Head and Neck Surgery, Perelman School of Medicine, University of Pennsylvania, Philadelphia

${ }^{4}$ Department of Neurology, Johns Hopkins University School of Medicine, Baltimore, MD

${ }^{5}$ Department of Radiology, the Johns Hopkins Hospital, Baltimore, MD

${ }^{6}$ Center for Neuroscience and Regenerative Medicine, Henry Jackson Foundation, Bethesda, MD

Keywords: multiple sclerosis, brain laterality, threshold, olfaction, UPSIT, magnetic resonance imaging, sex differences

Running head: Unilateral Olfaction and Multiple Sclerosis.

Address correspondence to: Richard L. Doty, Director, Smell and Taste Center, University of Pennsylvania School of Medicine, 5 Ravdin Building, 3400 Spruce Street, Philadelphia, PA 19104-4823. e-mail: richard.doty@uphs.upenn.edu 


\begin{abstract}
It is not known whether lateralized olfactory sensitivity deficits are present in MS. Since projections from the olfactory bulb to the olfactory cortex are largely ipsilateral, and since both functional imaging and psychophysical studies suggest that the right side of the brain may be more involved in olfactory processing than the left, we addressed this issue by administering well-validated tests of odor detection, along with tests of odor identification, to each side of the nose of 73 MS patients and 73 age-, gender-, and race-matched normal controls. We also determined, in 63 of the MS patients, whether correlations were present between the olfactory test measures and MRI-determined lesions in brain regions ipsilateral and contralateral to the nose side that was tested. No significant left:right differences in either olfactory sensitivity or identification were present, although in both cases mean performance was lower in the MS than in the control subjects (ps < 0.0001). Scores on the two sides of the nose were positively correlated with one another (identification $r=0.71, p<0.0001$; threshold $r=0.56, p<0.0001$ ). The percent of MS patients whose bilateral test scores fell below the $10^{\text {th }}$ percentile of controls did not differ between the odor identification and detection threshold tests. Both left and right odor identification and detection test scores were weakly correlated with lesion volumes in temporal and frontal lobe brain regions (r's $<0.40)$. Our findings demonstrate that MS does not differentially influence odor perception on left and right sides of the nose, regardless of whether sensitivity or identification is being measured. They also indicate that tests of odor identification and detection are similarly influenced by MS and that such influences are associated with central brain lesions.
\end{abstract}

Keywords: olfaction, multiple sclerosis, brain laterality, threshold, odor identification, UPSIT, MRI 


\section{Introduction}

Multiple sclerosis (MS), the most common cause of neurologic disability in the young adult, is characterized pathologically by central nervous system (CNS) demyelination. This disorder afflicts millions of people worldwide [1] and is known to alter the function of a number of sensory systems [2-5]. However, the influence of MS on the ability to smell has been a subject of controversy for at least two reasons. First, in contrast to the myelinated optic nerves, the axons of the olfactory nerve, i.e., Cranial Nerve I, are unmyelinated, leading some view the olfactory system as largely unmyelinated and, thus, unaffected by MS $[6,7]$. Second, published psychophysical studies on this topic are conflicting, with some reporting no MS-related influences on either threshold [8] or suprathreshold measures [9], whereas others reporting identification or threshold deficits in $10 \%$ to $80 \%$ of the evaluated patients [10-22]. While it is true that the olfactory receptor neurons themselves are unmyelinated, the centripetal projections from the mitral and tufted cells of the olfactory bulb are myelinated, as are multiple regions of the brain associated with olfactory transduction [23], essentially negating the notion that olfactory function should be spared from the influences of MS. It is noteworthy that authoritative MS textbooks fail to mention impaired olfaction as a possible pathognomonic sign (e.g., [24-26]).

There is evidence from functional imaging and psychophysical studies that the right hemisphere may be more involved in olfactory processing than the left [27-29]. In the case of MS, an impaired cortical network has been found whose nexus is within the right hemisphere [30]. Moreover, greater right-side damage to the locus coeruleus has been noted in MS which could differentially influence right hemisphere attentional processes [31]. Since the olfactory projections from the bulb to cortical regions are largely ipsilateral, it is conceivable that patients with MS may be less sensitive to smells on the right than on the left side of the nose. Although tests of odor identification have failed to show laterality effects in MS [32], some investigators have argued that threshold tests may be more sensitive than identification tests to MS-related olfactory deficits [33], particularly in regards to peripheral segments of the olfactory system, conceivably making thresholds more sensitive to lateralized deficits [34]. Regardless of whether laterality is present, however, an understanding of the relationship between olfactory threshold scores and lesions within olfactory eloquent brain structures remains to be determined.

The present study had three primary goals: first, to confirm that olfactory thresholds, as measured by a well-validated forced-choice test, are influenced by MS; second, to ascertain whether asymmetry, i.e., left-right nostril differences, occur in such scores; and third, to determine whether the threshold and identification test scores are correlated with the number and volume of MS-related lesions in central brain regions, most notably those ipsilateral to the side of the nose being tested. This study also sought to 
establish the degree of correlation between the two test measures and whether the left- and right-side test scores correlate with one another.

\section{Materials and Methods}

\subsection{Subjects}

Seventy three MS patients and 73 healthy controls matched on age, gender, and ethnicity participated in this study (see Table 1 for subject demographics). Although the proportion of smokers within each group did not differ significantly, the male MS patients had the highest cumulative levels of smoking (as measured by pack-years), whereas female control subjects had the lowest cumulative levels $\left[\mathrm{F}_{(3,24)}=4.6, \mathrm{p}<.02\right.$; Tukey's HSD $\left.\mathrm{p}<.02\right]$. All other groups did not differ from one another on this measure. No differences were present between male and female MS patients on duration of illness or on the Expanded Disability Status Scale (EDSS) score.

Participants were excluded from consideration if they had a medical history positive for a disorder in addition to MS that might influence olfaction. These included Bell's palsy, chronic rhinosinusitis, chronic lung infection, nasal polyposis, epilepsy, emphysema, liver disease, stroke, seizure disorder, neurodegenerative disease, schizophrenia, psychosis, bipolar disorder, dementia, amnesia, depression requiring medication or hospitalization, chronic alcoholism or drug abuse, brain surgery, or facial injuries or head trauma leading to loss of consciousness, among others. Approximately half came from within the University of Pennsylvania Medical System, whereas the remainder came from outside this system. Most patients learned of the study through their physician, MS support group, or a local MS newsletter.

Controls learned of the study either through their participant MS spouses or through advertisements placed in newspapers or fliers posted in the Hospital of the University of Pennsylvania or around the University's campus. Each subject was compensated for participation, provided with a free lunch, and reimbursed for parking or transportation costs to and from the testing site. The study was approved by the University's Office of Regulatory Affairs and all subjects provided informed written consent.

\section{INSERT TABLE 1 ABOUT HERE}

\subsection{Testing Protocol}

The 146 subjects underwent a comprehensive battery of olfactory, gustatory, auditory, vestibular, imaging, and neuropsychological tests that required, in total, $\sim 8$ hours for completion. The olfactory tests were the first, and the MRI imaging scans the last, of the procedures administered on a test day. Findings from non-olfactory components of this program have been published, or are being published, elsewhere (e.g., $[5,35])$. In rare cases, the test sessions were distributed across two days, depending upon a subject's availability, health, and tolerance for the testing procedures. Appropriate rest periods were provided between tests. Additionally, the test day was broken up by an hour-long lunch break. 
Two olfactory tests were administered to each side of the nose separately, with the non-tested side being occluded by a small piece of Microfoam ${ }^{\mathrm{TM}}$ tape (3M Corp. Minneapolis MN). The side of nose that was tested first was counterbalanced across subjects. Olfactory sensitivity was measured using an odor detection threshold test that employed the rose-like odorant phenyl ethyl alcohol (PEA), as described in detail elsewhere [36-40]. A single staircase procedure was used, with the staircase beginning at the -6.00 $\log$ concentration step of a half-log step (vol/vol) dilution series that extended from $-10.00 \log$ concentration to $-2.00 \log$ concentration. The odorant concentration was increased in full log steps until correct detection occurred on five sets of consecutive trials at a given concentration. If an incorrect response was given on any trial, the staircase was moved upward one full log step. When correct responses were made on all five trials, the staircase was reversed and subsequently moved up or down in $0.50 \log$ increments or decrements, depending upon the subject's performance on two pairs of trials at each concentration step. If the subject missed the first of these two trials, the second was not administered, and the next higher $0.50 \mathrm{log}$ concentration was presented. The average of last four of seven staircase reversals served as the threshold measure. Odor identification ability was tested using the University of Pennsylvania Smell Identification Test (UPSIT) [22]. In this test, the subject's task is to identify, in a 4alternative multiple choice format, each of 40 odorants presented on microencapsulated "scratch and sniff” labels. For example, one of the test items reads, "This odor smells most like: (a) chocolate; (b) banana; (c) onion; or (d) fruit punch". The subject was required to provide a response even if no odor was perceived (i.e., the test is forced-choice). The dependent measure is the number of items correctly answered. For the present purposes, two booklets of the test (20 items) were administered to the left naris and two booklets (20 items) to the right naris, with the booklets systematically counterbalanced among subjects. For heuristic purposes, the total unirhinal UPSIT score (maximum 20) for each side of the nose was doubled, allowing for general interpretation of the data within well-established 40-item UPSIT parameters. This procedure was justified, since the doubled mean UPSIT score for the best functioning side of the nose of the controls (36.6) was exactly the same as the median test score of subjects within the 45-49 age category of the bilateral UPSIT normative database comprised of nearly 4,000 subjects [41]. It is well established that the side of the nose with the higher score is the best predictor of bilateral function $[40,42]$.

\subsection{Magnetic Resonance Imaging of Brain}

All MS patients underwent, usually on the same day as the sensory testing, thin section magnetic resonance imaging (MRI) of the brain with gadolinium enhancement using a General Electric (Milwaukee, WI) 1.5-T Signal scanner employing a standard head coil. Usable images were available for 63 of the patients and were employed to quantify the number of lesions and volumes in multiple brain regions. The MRI evaluations included fluid-attenuated inversion recovery (FLAIR) and double-echo long-TR axial scans with 3-mm thick slices through the entire brain. The matrix was $256 \mathrm{x} 192$ pixels and the field of view was $240 \mathrm{~mm} 2$, allowing for detailed assessment of MS-related lesion intensity within 
selected brain regions. Brain volumes were extracted semi-automatically using a combination of interactive thresholding to disconnect the brain tissues from skull and dural boundaries, followed by morphological operators, and region growing to obtain an initial brain mask, followed by manual refinement $[43,44]$. A manual correction of the mask was then performed within a triplanar view using the MIPAV software package [44] and the mask was applied to each MRI contrast to extract the brain. Lesions were then defined semi-automatically by first using a fuzzy segmentation algorithm applied to the multichannel brain extracted images $[45,46]$. This algorithm was modified to model lesion intensities by including an as outlier class in the clustering functions, similar to the approach described by Van Leemput et al. [47]. The resulting segmentation was inclusive of all lesions but included falsepositives. All false positives that were manually removed by a trained operator within the MIPAV software package. . If a lesion fell into two regions, it was counted as a lesion in both of the regions. However, its volume was parceled between the two regions into which it fell. The intra-rater reliability intraclass correlation coefficient for our approach

based upon 10 cases repeated twice by the same operator (JC) was above 0.99 . Regions of interest (ROIs) were defined automatically by applying a high-dimensional, non-linear registration of a manually parcellated atlas image to each subject [48]. This approach, called HAMMER, uses geometric moments to determine correspondences between the atlas and the subject image in computing a smooth deformation field that maps the two brains. ROIs from the atlas were transferred to the subject image using this mapping. Twenty four brain regions were defined (Table 2).

\section{INSERT TABLE 2 ABOUT HERE}

\subsection{Statistical Analysis}

All analyses were performed using SPSS (v.21). The multivariate analyses on olfactory test scores were performed using GLM ANCOVAs with UPSIT or detection threshold scores as dependent variables and subject group (patient vs. control) and gender (male vs. female) as between-group factors and side of nose (left vs. right) as a within subject factor. Age served as a covariate. To assess relationships between the left and right olfactory test scores, as well as between the two types of tests, Pearson correlation coefficients were employed. Categorical comparisons were performed using $\chi^{2}$. Correlations between the test scores and disease duration were assessed after parceling out the effects of age. Similarly, correlations were computed between olfactory test scores and the number and volumes of lesions within brain structures with adequate numbers of lesions, as described in detail elsewhere $[5,35]$. In the case of lesion volumes, corrections for whole brain volumes were made. Because the lesion frequency distributions were not normal, we performed the analyses on square root-transformed data. One-tailed pvalues were unadjusted for multiple comparisons to avoid type II errors and associated problems [49, 50]; however, the number of computations was limited to subgroups with lesion activity and to olfactory eloquent brain structures. In these analyses, the lesion data from the left and right sides of the brain were retained as separate entities in light of possible lateralized associations with lesions in some brain regions.

\section{Results}

The mean olfactory test scores are presented in Figure 1. On average, the threshold scores were higher, i.e., sensitivity was lower, for the MS patients than for the controls [respective means $(\mathrm{SEM})=$ 
$-5.19(0.15) \&-6.01(0.14)$; subject group $\left.\mathrm{F}_{(1,141)}=13.0, \mathrm{p}<0.001, \eta^{2}=0.084\right]$. Similarly, the UPSIT scores were lower for the MS patients than for the controls [respective means (SDs) $=32.49(0.63) \&$ 34.99 (0.30); subject group $\left.\mathrm{F}(1,141)=13.8, \mathrm{p}<0.001, \eta^{2}=0.089\right]$. It is important to note that $19.2 \%$ of the MS patients had threshold test scores that fell below the $10^{\text {th }}$ percentile of controls $\left(\chi^{2}=3.73, \mathrm{p}<\right.$ $0.05)$, as compared to $28.8 \%$ for the UPSIT $\left(\chi^{2}=6.04, \mathrm{p}<0.02\right)$, although these percentages did not differ significantly $\left(\chi^{2}=0.026, p=0.872\right)$. When the UPSIT scores of the better performing side of the nose, which is the best estimate of bilateral function, were compared to sex- and age-adjusted normative control data obtained from nearly 4,000 subjects [41], 37\% of the MS patients exhibited some degree of smell loss $\left(\chi^{2}=6.74, \mathrm{p}<0.009\right)$.

No differences in threshold scores were observed between the left and right sides of the nose for the combined MS and control groups $\left[\mathrm{F}_{(1,141)}=1.09, \mathrm{p}=0.298, \eta^{2}=0.008\right]$. This was not the case, however, for the UPSIT scores, which proved to be slightly higher on the right than on the left side of the nose [respective means $(\mathrm{SEM})=34.15(0.37) \& 33.34(0.44)$; nose side $\mathrm{F}_{(1,141)}=8.0, \mathrm{p}<0.005, \eta^{2}=$ 0.054]. An age-related decline in UPSIT scores was found for the right, but not for the left, side of the nose [age by nose side interaction $\mathrm{F}_{(1,141)}=10.9, \mathrm{p}<0.002, \eta^{2}=0.072$; right $\mathrm{r}=-0.34, \mathrm{p}<0.001$; left $\mathrm{r}=$ $-0.14, \mathrm{~ns}]$.

In the case of the olfactory thresholds, a significant two-way interaction between gender and side of nose was present $\left[\mathrm{F}_{(1,141)}=5.6, \mathrm{p}<0.02, \eta^{2}=0.038\right]$, reflecting the tendency for women, independent of whether they had MS, to perform better on the left, and men on the right, side of the nose. However, posthoc comparisons found no significant differences between these means, although for males, the withinsubject comparison just failed to reach statistical significance $\left[\mathrm{t}_{(41)}=1.91, \mathrm{p}=0.063\right]$. No differences were observed in females $\left[\mathrm{t}_{(41)}=1.48, \mathrm{p}=0.142\right]$.

\section{INSERT FIGURE 1 ABOUT HERE}

Within the MS group, significant positive correlations were found between the two sides of the nose for both the threshold and identification test measures (threshold $\mathrm{r}=0.56, \mathrm{p}<0.0001$; UPSIT $\mathrm{r}=$ 0.71; $\mathrm{p}<0.0001)$. Significant correlations were also present in the MS subjects between the odor identification and threshold tests, with the right threshold scores correlating with both right and left UPSIT scores (respective r's $=0.24 \& 0.30$, ps $<0.05$ ) and the left threshold scores correlating with left, but not right, UPSIT scores [respective r's $=0.28(\mathrm{p}<0.05) \& 0.09(\mathrm{~ns})]$. No significant correlations were found between disease duration and either the odor identification or the detection threshold test scores (ps > 0.20). Although UPSIT scores, but not thresholds, were nominally higher for individuals whose disease duration was $\leq 2$ years than for those whose disease duration was $>2$ years $(\mathrm{p}<0.003)$, the inclusion of age as a covariate eliminated this association $(\mathrm{p}=0.227)$. 
Significant correlations were present between right-side threshold sensitivity scores with lesion volumes in the right and left temporal lobes [respective rs $(\mathrm{ps})=-.27(0.02) \&-0.31(0.008)]$. Similar correlations were also evident between right-side UPSIT scores and lesion volumes in the right cortex $(\mathrm{r}=$ $-32, \mathrm{p}<0.007)$, left cortex $(\mathrm{r}=-0.27, \mathrm{p}=0.02)$, right medial frontal lobe $(\mathrm{r}=-0.36, \mathrm{p}=0.003)$, and left medial frontal lobe $(r=-0.29, p=0.013)$. Left side UPSIT scores inversely correlated with lesion volumes in the right cerebral cortex $(r=-.30, p=0.01)$, left cerebral cortex $(r=-0.23, p<0.039)$, right medial frontal cortex $(r=-0.28, p<0.016)$, left medial frontal cortex $(r=-0.25, p<0.031)$, and right superior frontal cortex $(r=-0.27, \mathrm{p}<0.029) \quad$ No other meaningful relationships were observed.

\section{Discussion}

The present study, using a comparatively large number of MS patients and controls, clearly demonstrates that while MS adversely influences both olfactory sensitivity and odor identification test scores to some degree, the deficits are not lateralized to one side of the nose or the other. Indeed, the leftand right-side scores of both of these tests correlated strongly with one another. The percent of MS patients whose odor detection and identification test scores fell below the $10^{\text {th }}$ percentile of controls was similar. These observations, along with the fact that the odor identification and threshold test scores were correlated, suggest that common physiological processes likely influence both types of test measures. This concept of commonality receives additional support from our finding of a similar pattern of correlations between the test measures and lesion numbers and volumes within the temporal and frontal lobe brain regions. Commonality between odor identification and detection thresholds appears to be present in diseases other than MS. [51]. Thus, individuals with Alzheimer's disease [52], Parkinson's disease [53], and epilepsy [54] - diseases whose impact on olfaction is most likely dependent upon pathologies within the brain -- exhibit both odor identification and detection threshold deficits. In aggregate, such observations throw into question the general notion that tests of odor detection and identification are differentially measuring peripheral and central elements of olfactory processing [34].

We found no relationship between disease duration and either the detection or the identification test scores when subject age was taken into account. This lack of association remained even after we segregated disease duration into less than or more than two years, as was previously done by Lutterotti et al. [16]. The latter investigators reported that MS patients with a disease duration < 2 years were less sensitive than those with a disease duration $>2$ years and that a negative correlation $(r=-0.43)$ was present between disease duration and odor identification test scores. Rolet et al. [33] similarly suggested that olfactory threshold impairment may be more prevalent early in the course of the disease and noted that detection thresholds were lower in those patients who had a relapse in the previous 2 years $(p=0.06)$, but did not find any evidence that odor identification was associated with disease duration. The reason(s) 
for the differences between our findings and those of these earlier studies are not clear. We employed a slightly larger sample size of MS patients (73 vs. 50 in each the other studies), arguably more reliable olfactory tests $[22,38,55]$, and subjects who were screened to eliminate comorbidities that could influence a range of sensory and cognitive test measures, thereby resulting in an exceptionally 'pure' cohort of MS subjects. We also employed an age covariate in our correlation assessments.

It is noteworthy that the proportion of our $73 \mathrm{MS}$ patients with odor identification losses relative to absolute values obtained from normative data (i.e., UPSIT scores $<34$ for men and $<35$ for women) was nearly identical to that found in our 1997 study of 26 MS patients (37\% vs. 38.5\%, respectively). ${ }^{1}$ This value is similar to that reported by Lutterotti et al. [16] for their identification test that employed Sniffin' Sticks and published normative data (38\%). It is also worthy of note that the proportion of our MS patients whose UPSIT scores fell below the $10^{\text {th }}$ percentile of those of their age- and sex-matched controls was similar to that of the UPSIT scores falling outside of the $95^{\text {th }}$ confidence interval of normal subjects in a study performed on 72 MS patients by Hawkes et al. [20]. Similar proportions of patients were deemed abnormal in a study by Zorzon and colleagues [18] of 40 MS patients that employed the Brief Smell Identification Test (B-SIT) (22.5\%) [56], as well as in a similar B-SIT study by Silva et al. of 153 MS patients $(32 \%)$.

Our finding of no systematic lateralized differences in threshold sensitivity in healthy subjects is in agreement with earlier studies [40, 42, 57-59], although the tendency for women of the combined MS and control group to exhibit better sensitivity on the left and for men to have better sensitivity on the right, has not been previously observed. This phenomenon was not strong, as follow up contrasts on the interaction did not reach statistically significance. Nevertheless, it is interesting that this finding is similar to that reported by Doty and Kerr [57] for a 12-trial match-to-sample odor memory/discrimination task. Women, but not men, performed better on the left than on the right side of the nose.

One goal of the present research was to assess potential differences between the two sides of the nose in odor detection and identification. Despite the fact that no left:right differences were apparent in either the MS patients or the controls for the sensitivity measure, odor identification test scores were slightly higher on the right than the left of the combined MS and control subject groups. Moreover, an age-related decline in odor identification was present on the right, but not on the left, side of the nose in this combined group. While previous odor identification studies have not observed such laterality in either healthy subjects or patients with neurological diseases (for example [60-63]), superior right-side performance has been noted in healthy subjects for several other types of suprathreshold tests, including a same-different odor discrimination task [57] and tests of odorant intensity [29, 64]. It is conceivable that,

\footnotetext{
${ }^{1}$ The data used in this assessment from the current study was that of the better functioning side of the nose, since generally bilateral test scores reflect the better functioning side [42].
} 
in our study, the greater range of test scores on the right side of the nose made it easier to unmask the agerelated deficit known to occur in most odor identification studies [22, 65]. It should be emphasized, as noted in the introduction, that numerous studies, particularly those involving functional imaging, have found greater involvement of the right than the left hemisphere in olfactory processing [66]. More research is clearly needed to better define the reasons for the aforementioned discrepancies.

The correlations found in the present study between UPSIT scores and MS-related lesions within the temporal and frontal lobes were considerably smaller than those of our earlier work $(<-0.35$ vs. $>$ -0.90) [21, 32]. We have no specific explanation for this difference. Potential reasons include (a) possible differences in the definition of the imaged brain regions, (b) heterogeneity of lesion activity among subjects, including lesion distributions, (c) the assessment of unilateral rather than bilateral olfactory function with 20, rather than 40, test items per side, and (d) different sample sizes and lesion counting procedures (manual vs. machine-based), including threshold setting for lesion detection and identification of major lesions. There is evidence that some automated procedures for identifying MSrelated lesions dilute the MRI measure by providing lesion information that is not normally recognized by the eye [67]. It should be pointed out, however, that conflicting findings have appeared among the few studies that have examined relationships between olfactory test scores and MS-related lesions within olfactory eloquent structures, i.e., the orbitofrontal and medial and posterior temporal cortices. Zorzon [18], for example, reported a - 0.74 correlation between score on the B-SIT and MR measures of white matter lesion load in such structures in $40 \mathrm{MS}$ patients. After correcting for potential confounders, this association reached the level of the correlations found in our previous work $(r=-0.90, p<0.0001)$. In contrast, Li et al. [68] and Rolet et al. [33] found no associations between MR-related brain lesions and their olfactory test measures, which were comprised of detection and recognition thresholds (Li et al) and Sniffin' Sticks measures (Rolet et al.). The MRI scans employed by Rolet et al., which were not described in detail, were taken a year before their olfactory testing, unlike the situation in our study where the scans, in nearly all cases, were performed on the same day of testing. While Erb et al. [69] similarly found no meaningful associations between Sniffin' Sticks measures and lesion load within olfactory eloquent brain regions, they did observe a -0.68 correlation between their odor identification test scores and fractional anisotropy of the lesions and the surrounding normal-appearing brain tissue, as measured by diffusion tensor imaging.

Our study has both strengths and weaknesses. Among its strengths are its (a) relatively large sample size characterized by MS and control subjects matched on age, sex, and ethnicity, (b) wellvalidated and highly reliable tests of both odor identification and detection, and (c) sophisticated means for assessing MS-related lesion numbers and volumes in multiple brain regions. Among its weaknesses are the computations of a considerable number of correlations between the olfactory test measures and the 
brain lesion measures, potentially inflating the type I error rate and leading to some spurious associations in our correlation analyses. However, there is always a trade-off between type I and type II errors and the correlations we observed were in the brain regions and direction that would be expected from previous research on this topic. Importantly, the number of computations was limited to subgroups with lesion activity and to olfactory eloquent structures. Another concern would be that the olfactory testing was performed along with a number of tests on the same day. It is unlikely that this influenced our olfactory tests, since they were always performed first thing in the morning.

\subsection{Conclusion}

This study, the largest of its type to date, demonstrates that MS-related deficits in odor detection sensitivity and odor identification are not lateralized and are correlated with one another across the two sides of the nose. Moreover, it shows that tests of detection and identification are closely related to one another and that both types of tests are inversely correlated with MS-related lesion volumes within olfactory eloquent brain regions. In accord with earlier studies on this topic, the average MS-related decrement, while statistically significant, were found to be not large, with a significant number of MS patients exhibiting relatively normal smell function.

\section{Acknowledgments \& Disclosure}

Supported by grants from the National Institutes of Health (RO1 DC 02974) and the Department of Defense (USAMRAA W81XWH-09-1-0467). We are grateful to the following persons for their help on the study: Lloyd Hastings, Kara-Lynne Kerr, Cheng Li, Clyde Markowitz, Gul Moonis, Bala Palecanda, Steven Pulitzer, Mary Sammel, and Jay Udapa. RLD is President and major shareholder of Sensonics International, the company that manufactures and distributes the commercial version of the University of Pennsylvania Smell Identification Test (UPSIT).

\section{References}

1. Pirko, I.; Noseworthy, J. H. Demyelinated disorders of the central nervous system. In: Goetz, C. G. Textbook of Clinical Neurology. Philadelphia: Saunders; 2003:p1059-1082.

2. Gianni, C.; Prosperini, L.; Jonsdottir, J.; Cattaneo, D. A systematic review of factors associated with accidental falls in people with multiple sclerosis: a meta-analytic approach. Clin. Rehabil. 2014, 28:704-716.

3. Arnold, J. E.; Bender, D. R. BSER abnormalities in a multiple sclerosis patient with normal peripheral hearing acuity. Am. J. Otol. 1983, 4:235-237. 
4. Fritz, N. E.; Marasigan, R. E.; Calabresi, P. A.; Newsome, S. D.; Zackowski, K. M. The impact of dynamic balance measures on walking performance in multiple sclerosis. Neurorehabil. Neural Repair 2015, 29:62-69.

5. Doty, R. L.; Tourbier, I. A.; Pham, D. L.; Cuzzocreo, J. L.; Udupa, J. K.; Karacali, B.; Beals, E.; Fabius, L.; Leon-Sarmiento, F. E.; Moonis, G.; Kim, T.; Mihama, T.; Geckle, R. J.; Yousem, D. M. Taste dysfunction in multiple sclerosis. J. Neurol. 2016, 263:677-688.

6. Lumsden, C. E. The neuropathology of multiple sclerosis. In: Vinken, P. J. and Bruyn, G. W. Handbook of Clinical Neurology, Multiple Sclerosis and Other Demyelination Diseases. Amsterdam: North-Holland Publishing Co.; 1970:p217-309.

7. Zimmerman, M. H.; NETSKY, M. G. The pathology of multiple sclerosis. Res. Publ. Assoc. Res. Nerv. Ment. Dis. 1950, 28:271-312.

8. Ansari, K. A. Olfaction in multiple sclerosis. With a note on the discrepancy between optic and olfactory involvement. European Neurology 1976, 14:138-145.

9. Kesslak, J. P.; Cotman, C. W.; Chui, H. C.; van den Noort, S.; Fang, H.; Pfeffer, R.; Lynch, G. Olfactory tests as possible probes for detecting and monitoring Alzheimer's disease. Neurobiol Aging 1988, 9:399-403.

10. Pinching, A. J. Clinical testing of olfaction reassessed. Brain 1977, 100:377-388.

11. DeLuca, G. C.; Joseph, A.; George, J.; Yates, R. L.; Hamard, M.; Hofer, M.; Esiri, M. M. Olfactory Pathology in Central Nervous System Demyelinating Diseases. Brain Pathol. 2015, 25:543-551.

12. Caminiti, F.; De, S. S.; De Cola, M. C.; Russo, M.; Bramanti, P.; Marino, S.; Ciurleo, R. Detection of olfactory dysfunction using olfactory event related potentials in young patients with multiple sclerosis. PLoS. One. 2014, 9:e103151.

13. Schmidt, F.; Goktas, O.; Jarius, S.; Wildemann, B.; Ruprecht, K.; Paul, F.; Harms, L. Olfactory dysfunction in patients with neuromyelitis optica. Mult. Scler. Int. 2013, 2013:654501.

14. Silva, A. M.; Santos, E.; Moreira, I.; Bettencourt, A.; Coutinho, E.; Goncalves, A.; Pinto, C.; Montalban, X.; Cavaco, S. Olfactory dysfunction in multiple sclerosis: association with secondary progression. Mult. Scler. 2012, 18:616-621.

15. Goektas, O.; Schmidt, F.; Bohner, G.; Erb, K.; Ludemann, L.; Dahlslett, B.; Harms, L.; Fleiner, F. Olfactory bulb volume and olfactory function in patients with multiple sclerosis. Rhinology 2011, 49:221-226.

16. Lutterotti, A.; Vedovello, M.; Reindl, M.; Ehling, R.; DiPauli, F.; Kuenz, B.; Gneiss, C.; Deisenhammer, F.; Berger, T. Olfactory threshold is impaired in early, active multiple sclerosis. Mult. Scler. 2011, 17:964-969.

17. Fleiner, F.; Dahlslett, S. B.; Schmidt, F.; Harms, L.; Goektas, O. Olfactory and gustatory function in patients with multiple sclerosis. Am. J. Rhinol. Allergy 2010, 24:e93-e97.

18. Zorzon, M.; Ukmar, M.; Bragadin, L. M.; Zanier, F.; Antonello, R. M.; Cazzato, G.; Zivadinov, R. Olfactory dysfunction and extent of white matter abnormalities in multiple sclerosis: a clinical and MR study. Mult. Scler. 2000, 6:386-390. 
19. Zivadinov, R.; Zorzon, M.; Monti, B. L.; Pagliaro, G.; Cazzato, G. Olfactory loss in multiple sclerosis. J. Neurol. Sci. 1999, 168:127-130.

20. Hawkes, C. H.; Shephard, B. C.; Kobal, G. Assessment of olfaction in multiple sclerosis: evidence of dysfunction by olfactory evoked response and identification tests. Journal of Neurology, Neurosurgery \& Psychiatry 1997, 63:145-151.

21. Doty, R. L.; Li, C.; Mannon, L. J.; Yousem, D. M. Olfactory dysfunction in multiple sclerosis. New Engl. J. Med. 1997, 336:1918-1919.

22. Doty, R. L.; Shaman, P.; Dann, M. Development of the University of Pennsylvania Smell Identification Test: a standardized microencapsulated test of olfactory function. Physiology \& Behavior 1984, 32:489-502.

23. Garcia-Gonzalez, D.; Murcia-Belmonte, V.; Clemente, D.; de, C. F. Olfactory system and demyelination. Anat. Rec. (Hoboken. ) 2013, 296:1424-1434.

24. Raine, C. S.; McFarland, H.; Hohifeld, R. Multiple sclerosis: A comprehensive text. In. Philadelphia: Elsevier; 2008.

25. Cook, S. D. Handbook of Multiple Sclerosis. In. 4th ed. New York: Taylor \& Francis; 2006.

26. Compston, A.; McDonald, I. R.; Noseworthy, J.; Lassmann, H.; Miller, D. H.; Smith, K. J.; Wekerlie, H.; Confavreux, C. McAlpine's Multiple Sclerosis. In. 4th ed. London: Churchill Livingstone; 2005.

27. Zatorre, R. J.; Jones-Gotman, M.; Evans, A. C.; Meyer, E. Functional localization and lateralization of human olfactory cortex. Nature 1992, 360:339-340.

28. Renier, L.; Cuevas, I.; Grandin, C. B.; Dricot, L.; Plaza, P.; Lerens, E.; Rombaux, P.; De Volder, A. G. Right occipital cortex activation correlates with superior odor processing performance in the early blind. PLoS. One. 2013, 8:e71907.

29. Thuerauf, N.; Gossler, A.; Lunkenheimer, J.; Lunkenheimer, B.; Maihofner, C.; Bleich, S.; Kornhuber, J.; Markovic, K.; Reulbach, U. Olfactory lateralization: odor intensity but not the hedonic estimation is lateralized. Neurosci. Lett. 2008, 438:228-232.

30. Lenne, B.; Blanc, J. L.; Nandrino, J. L.; Gallois, P.; Hautecaeur, P.; Pezard, L. Decrease of mutual information in brain electrical activity of patients with relapsing-remitting multiple sclerosis. Behav. Neurol. 2013, 27:201-212.

31. Gadea, M.; Martinez-Bisbal, M. C.; Marti-Bonmati, L.; Espert, R.; Casanova, B.; Coret, F.; Celda, B. Spectroscopic axonal damage of the right locus coeruleus relates to selective attention impairment in early stage relapsing-remitting multiple sclerosis. Brain 2004, 127:89-98.

32. Doty, R. L.; Li, C.; Mannon, L. J.; Yousem, D. M. Olfactory dysfunction in multiple sclerosis. Relation to plaque load in inferior frontal and temporal lobes. Ann. N. Y. Acad. Sci. 1998, 855:781786.

33. Rolet, A.; Magnin, E.; Millot, J. L.; Berger, E.; Vidal, C.; Sileman, G.; Rumbach, L. Olfactory dysfunction in multiple sclerosis: evidence of a decrease in different aspects of olfactory function. Eur. Neurol. 2013, 69:166-170. 
34. Koss, E.; Weiffenbach, J. M.; Haxby, J. V.; Friedland, R. P. Olfactory detection and identification performance are dissociated in early Alzheimer's disease. Neurology 1988, 38:1228-1232.

35. Doty, R. L.; Tourbier, I.; Davis, S.; Rotz, J.; Cuzzocreo, J. L.; Treem, J.; Shephard, N.; Pham, D. L. Pure-tone auditory thresholds are not chronically elevated in multiple sclerosis. Behav. Neurosci. 2012, 126:314-324.

36. Doty, R. L.; Gregor, T. P.; Settle, R. G. Influence of intertrial interval and sniff-bottle volume on phenyl ethyl alcohol odor detection thresholds. Chem Senses 1986, 11:259-264.

37. Deems, D. A.; Doty, R. L. Age-related changes in the phenyl ethyl alcohol odor detection threshold. Transactions of the Pennsylvania Academy of Ophthalmology and Otolaryngology 1987, 39:646650.

38. Doty, R. L.; McKeown, D. A.; Lee, W. W.; Shaman, P. A study of the test-retest reliability of ten olfactory tests. Chem Senses 1995, 20:645-656.

39. Pierce, J. D., Jr.; Doty, R. L.; Amoore, J. E. Analysis of position of trial sequence and type of diluent on the detection threshold for phenyl ethyl alcohol using a single staircase method. Perceptual \& Motor Skills. 1996, 82:451-458.

40. Betchen, S. A.; Doty, R. L. Bilateral detection thresholds in dextrals and sinistrals reflect the more sensitive side of the nose, which is not lateralized. Chem Senses 1998, 23:453-457.

41. Doty, R. L. The Smell Identification Test ${ }^{\mathrm{TM}}$ Administration Manual -- 3rd Edition. Haddon Hts., NJ: Sensonics, Inc.; 1995.

42. Hornung, D. E.; Leopold, D. A.; Mozell, M. M.; Sheehe, P. R.; Youngentob, S. L. Impact of left and right nostril abilities on binasal olfactory performance. Chem Senses 1990, 15:233-237.

43. Goldszal, A. F.; Davatzikos, C.; Pham, D. L.; Yan, M. X.; Bryan, R. N.; Resnick, S. M. An imageprocessing system for qualitative and quantitative volumetric analysis of brain images. J Comp Assist Tomography 1998, 22:827-837.

44. Bazin, P. L.; Cuzzocreo, J. L.; Yassa, M. A.; Gandler, W.; McAuliffe, M. J.; Bassett, S. S.; Pham, D. L. Volumetric neuroimage analysis extensions for the MIPAV software package. J. Neurosci. Methods 2007, 165:111-121.

45. Pham, D. L.; Prince, J. L. Adaptive fuzzy segmentation of magnetic resonance images. IEEE Trans. Med. Imaging 1999, 18:737-752.

46. Pham, D. L. Spatial models for fuzzy clustering. Computerized Medical Imaging \& Graphics 2001, 84:285-297.

47. Van, L. K.; Maes, F.; Vandermeulen, D.; Colchester, A.; Suetens, P. Automated segmentation of multiple sclerosis lesions by model outlier detection. IEEE Trans. Med. Imaging 2001, 20:677-688.

48. Shen, D.; Davatzikos, C. HAMMER: hierarchical attribute matching mechanism for elastic registration. IEEE Trans. Med. Imaging 2002, 21:1421-1439.

49. Perneger, T. V. What's wrong with Bonferroni adjustments. BMJ 1998, 316:1236-1238. 
50. Rothman, K. J. No adjustments are needed for multiple comparisons. Epidemiology 1990, 1:43-46.

51. Doty, R. L.; Smith, R.; McKeown, D. A.; Raj, J. Tests of human olfactory function: principal components analysis suggests that most measure a common source of variance. Percept Psychophys 1994, 56:701-707.

52. Doty, R. L.; Reyes, P. F.; Gregor, T. Presence of both odor identification and detection deficits in Alzheimer's disease. Brain Research Bulletin 1987, 18:597-600.

53. Doty, R. L.; Deems, D. A.; Stellar, S. Olfactory dysfunction in parkinsonism: a general deficit unrelated to neurologic signs, disease stage, or disease duration. Neurology 1988, 38:1237-1244.

54. Doty, R. L.; Hawkes, C. H.; Good, K. P.; Duda, J. E. Odor perception and neuropathology in neurodegenerative diseases and schizophrenia. In: Doty, R. L. Handbook of Olfaction and Gustation. 3rd ed. Hoboken: John Wiley \& Sons; 2015: p 403-452.

55. Hummel, T.; Sekinger, B.; Wolf, S. R.; Pauli, E.; Kobal, G. 'Sniffin' sticks': olfactory performance assessed by the combined testing of odor identification, odor discrimination and olfactory threshold. Chem Senses 1997, 22:39-52.

56. Doty, R. L.; Marcus, A.; Lee, W. W. Development of the 12-item cross-cultural smell identification test (CC-SIT). Laryngoscope 1996, 106:353-356.

57. Zatorre, R. J.; Jones-Gotman, M. Right-nostril advantage for discrimination of odors. Percept Psychophys 1990, 47:526-531.

58. Koelega, H. S. Olfaction and sensory asymmetry. Chemical Senses and Flavour 1979, 4:89-95.

59. Eskenazi, B.; Cain, W. S.; Lipsitt, E. D.; Novelly, R. A. Olfactory functioning and callosotomy: a report of two cases. Yale J Biol Med 1988, 61:447-456.

60. Doty, R. L.; Stern, M. B.; Pfeiffer, C.; Gollomp, S. M.; Hurtig, H. I. Bilateral olfactory dysfunction in early stage treated and untreated idiopathic Parkinson's disease. J Neurol Neurosurg Psychiat 1992, 55:138-142.

61. Good, K. P.; Martzke, J. S.; Daoud, M. A.; Kopala, L. C. Unirhinal norms for the University of Pennsylvania Smell Identification Test. The Clinical Neuropsychologist 2003, 17:226-234.

62. Szeszko, P. R.; Bates, J.; Robinson, D.; Kane, J.; Bilder, R. M. Investigation of unirhinal olfactory identification in antipsychotic-free patients experiencing a first-episode schizophrenia. Schizophr. Res. 2004, 67:219-225.

63. Roalf, D. R.; Turetsky, B. I.; Owzar, K.; Balderston, C. C.; Johnson, S. C.; Brensinger, C. M.; Gur, R. E.; Siegel, S. J.; Moberg, P. J. Unirhinal olfactory function in schizophrenia patients and firstdegree relatives. J Neuropsychiat ClinNeurosci 2006, 18:389-396.

64. Pendse, S. G. Hemispheric asymmetry in olfaction on a category judgement task. Percept Mot Skills 1987, 64:495-498.

65. Murphy, C.; Shubert, C. R.; Cruickshanks, K. J.; Klein, B. E.; Nondahl, D. M. Prevalence of olfactory impairment in older adults. J Amer Med Assoc 2002, 288:2307-2312. 
66. Doty, R. L.; Bromley, S. M.; Moberg, P. J.; Hummel, T. Laterality in human nasal chemoreception. In: Christman, S. Cerebral Asymmetries in Sensory and Perceptual Processing. Amsterdam: North Holland Publishing Co.; 1997:p497-542.

67. Geurts, J. J.; Bo, L.; Pouwels, P. J.; Castelijns, J. A.; Polman, C. H.; Barkhof, F. Cortical lesions in multiple sclerosis: combined postmortem MR imaging and histopathology. AJNR Am. J. Neuroradiol. 2005, 26:572-577.

68. Li, L. M.; Yang, L. N.; Zhang, L. J.; Fu, Y.; Li, T.; Qi, Y.; Wang, J.; Zhang, D. Q.; Zhang, N.; Liu, J.; Yang, L. Olfactory dysfunction in patients with multiple sclerosis. J. Neurol. Sci. 2016, 365:3439.

69. Erb, K.; Bohner, G.; Harms, L.; Goektas, O.; Fleiner, F.; Dommes, E.; Schmidt, F. A.; Dahlslett, B.; Ludemann, L. Olfactory function in patients with multiple sclerosis: a diffusion tensor imaging study. J. Neurol. Sci. 2012, 316:56-60. 
Figure Captions:

Figure 1. Odor identification and detection threshold scores by subject group and sex. Abbreviations: MS Multiple Sclerosis, C: Controls, PEA: Phenyl ethyl alcohol test, UPSIT: University of Pennsylvania Smell Identification Test. See text for details.

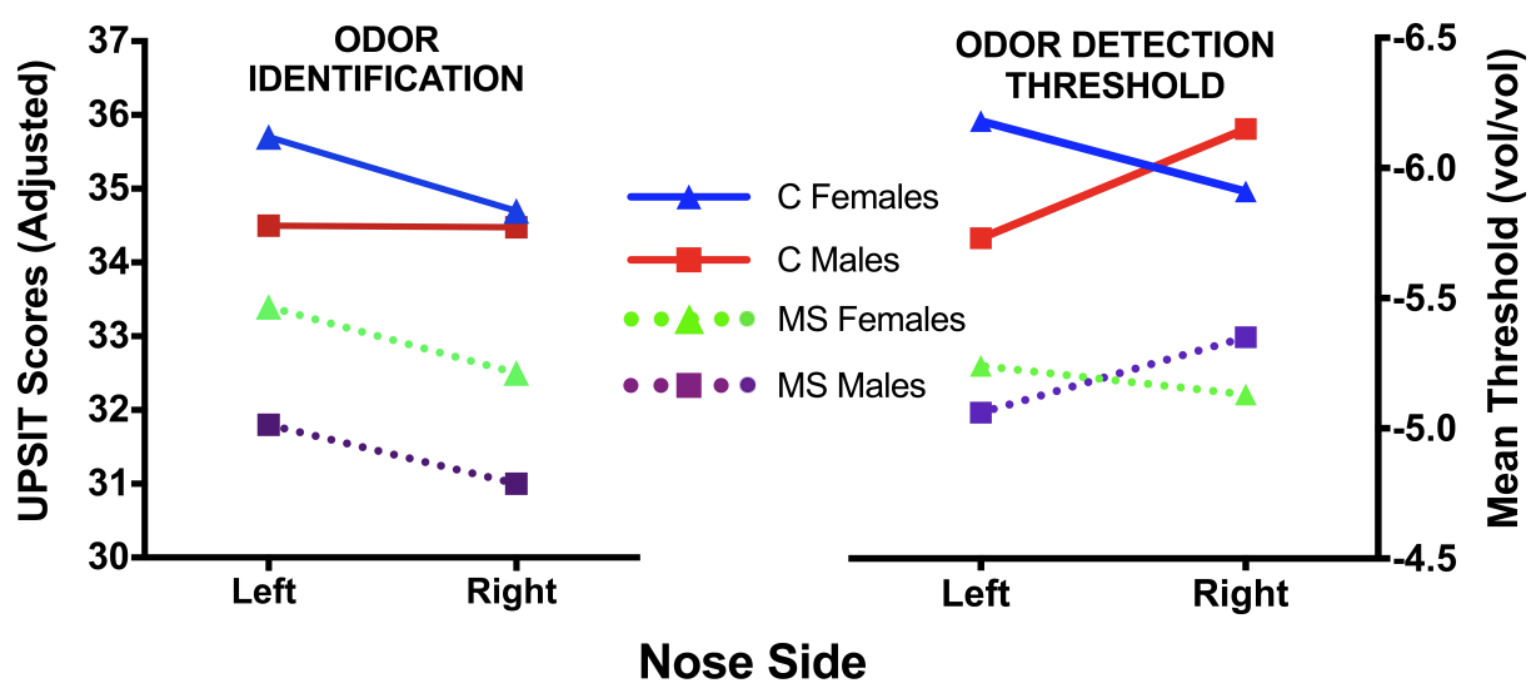


Table 1. Basic demographics of the MS and matched control subjects

\begin{tabular}{|c|c|c|c|c|c|c|c|c|}
\hline $\begin{array}{l}\text { Subject } \\
\text { Group }\end{array}$ & $\begin{array}{l}\text { Sample } \\
\text { Size }\end{array}$ & $\begin{array}{l}\text { Mean } \\
\text { Age } \\
\text { (SD) }\end{array}$ & $\begin{array}{c}\text { Ethnicity } \\
\text { W/B } \\
(\% \mathrm{~W})\end{array}$ & $\begin{array}{l}\text { Mean Yrs } \\
\text { Education } \\
\text { (SD) }\end{array}$ & $\begin{array}{c}\text { Number of } \\
\text { Smokers/Non- } \\
\text { Smokers } \\
\text { (\% Smokers) }\end{array}$ & $\begin{array}{c}\text { Mean (SD) } \\
\text { Disease } \\
\text { Duration }\end{array}$ & $\begin{array}{l}\text { Mean } \\
\text { EDSS } \\
\text { Score } \\
\text { (SD) }\end{array}$ & $\begin{array}{c}\text { Disease } \\
\text { Classification }\end{array}$ \\
\hline $\begin{array}{l}\text { MS - } \\
\text { Males }\end{array}$ & 21 & $\begin{array}{c}45.24 \\
(11.42)\end{array}$ & $\begin{array}{c}17 / 4 \\
(81.0)\end{array}$ & $15.10(2.74)$ & $\begin{array}{c}5 / 16 \\
(23.8 \%)\end{array}$ & $\begin{array}{c}6.86 \\
(3.90)\end{array}$ & $\begin{array}{c}4.54 \\
(1.80)\end{array}$ & $\begin{array}{l}\text { RR: } 15 ; \text { PP: } 2 \text {; } \\
\text { SP: } 2 ; \mathrm{U}: 2\end{array}$ \\
\hline $\begin{array}{c}\text { MS - } \\
\text { Females }\end{array}$ & 52 & $\begin{array}{l}45.60 \\
(8.61)\end{array}$ & $\begin{array}{l}38 / 14 \\
(73 \%)\end{array}$ & $14.51(2.20)$ & $\begin{array}{c}12 / 40 \\
(23.1 \%)\end{array}$ & $\begin{array}{c}8.13 \\
(6.88)\end{array}$ & $\begin{array}{c}3.32 \\
(1.66)\end{array}$ & $\begin{array}{l}\text { RR: 42; PP: } 1 \text {; } \\
\text { SP: 4; U: } 5\end{array}$ \\
\hline $\begin{array}{c}\mathrm{C}- \\
\text { Males }\end{array}$ & 21 & $\begin{array}{c}45.43 \\
(10.78)\end{array}$ & $\begin{array}{c}17 / 4 \\
(81.0)\end{array}$ & $15.10(3.22)$ & $\begin{array}{c}4 / 17 \\
(19.0 \%)\end{array}$ & ---- & ---- & ---- \\
\hline $\begin{array}{c}\text { C- } \\
\text { Females }\end{array}$ & 52 & $\begin{array}{c}46.0 \\
(9.35)\end{array}$ & $\begin{array}{c}38 / 14 \\
(73.1 \%)\end{array}$ & $15.51(2.36)$ & $\begin{array}{c}5 / 47 \\
(9.6 \%)\end{array}$ & ---- & ---- & ---- \\
\hline
\end{tabular}

Abbreviations: $\mathrm{w} / \mathrm{b}=$ white/black; $\mathrm{MS}=$ multiple sclerosis; $\mathrm{C}=$ control; $\mathrm{RR}=$ relapsing remitting; $\mathrm{PP}=$ Primary progressive; $\mathrm{SP}=$ secondary progressive; $\mathrm{U}=$ Unknown. EDSS $=$ Expanded Disability Status Score based on 22 patients. No significant differences are present between any of the means or frequencies across the MS and control groups or between the males and females. 
Table 2. Details of Lesion Activity in Target Brain Regions. See text for details.

\begin{tabular}{|c|c|c|c|}
\hline Brain Region & $\begin{array}{c}\text { Number of } \\
\text { Subjects } \\
\text { with } \\
\text { Lesions }\end{array}$ & $\begin{array}{l}\text { Mean (SD) Volume of } \\
\text { Lesions (SD) }\end{array}$ & $\begin{array}{c}\text { Mean lesion } \\
\text { numbers (SD) }\end{array}$ \\
\hline Cortex L & 63 & $6537.5(5383.9)$ & $33.6(22.8)$ \\
\hline Cortex R & 63 & $6396.4(5106.4)$ & $32.6(20.2)$ \\
\hline Medial Frontal Lobe L & 63 & $1503.7(1511.2)$ & $14.9(10.7)$ \\
\hline Medial Frontal Lobe R & 63 & $1526.9(1623.8)$ & $13.3(7.0)$ \\
\hline Temporal Lobe L & 63 & $1170.7(1200.3)$ & $13.2(8.3)$ \\
\hline Temporal Lobe $\mathrm{R}$ & 61 & 1158.1(1205.0) & $16.0(8.7)$ \\
\hline Medial Temp Lobe L & 56 & $62.3(66.5)$ & $6.0(4.2)$ \\
\hline Medial Temp Lobe $\mathrm{R}$ & 56 & $90.9(86.0)$ & $7.9(5.0)$ \\
\hline Superior Frontal Lobe L & 60 & $541.3(845.0)$ & $6.6(4.9)$ \\
\hline Superior Frontal Lobe $\mathbf{R}$ & 54 & $468.3(648.4)$ & $5.7(5.1)$ \\
\hline Hippocampus L & 48 & $52.9(59.2)$ & $4.5(3.0)$ \\
\hline Hippocampus R & 47 & $49.8(56.6)$ & $4.7(3.0)$ \\
\hline Inferior Frontal Lobe L & 46 & $121.5(176.2)$ & $5.6(5.4)$ \\
\hline Inferior Frontal Lobe R & 48 & $102.4(157.0)$ & $5.6(5.6)$ \\
\hline Insular White Matter L & 39 & $28.4(42.2)$ & $3.2(4.1)$ \\
\hline Insular White Matter R & 42 & $24.3(28.9)$ & $3.1(2.5)$ \\
\hline Insular Grey Matter L & 36 & $40.8(84.2)$ & $3.5(3.9)$ \\
\hline Insular Grey Matter R & 39 & $34.9(42.1)$ & $3.2(2.7)$ \\
\hline $\begin{array}{l}\text { Anterior Cingulate } \\
\text { Gyrus L }\end{array}$ & 37 & $19.8(27.2)$ & $2.1(2.0)$ \\
\hline $\begin{array}{l}\text { Anterior Cingulate } \\
\text { Gyrus R }\end{array}$ & 36 & $44.4(104.9)$ & $2.6(2.0)$ \\
\hline Orbitofrontal Cortex L & 38 & $45.3(51.5)$ & $3.0(1.8)$ \\
\hline Orbitofrontal Cortex R & 36 & $41.6(57.0)$ & $3.2(2.7)$ \\
\hline Thalamus L & 30 & $34.2(52.4)$ & $3.0(2.3)$ \\
\hline Thalamus $\mathbf{R}$ & 32 & $26.9(58.4)$ & $3.0(2.5)$ \\
\hline
\end{tabular}

${ }^{1}$ volumes are in $\mathrm{mm}^{3}$ 